\title{
Fundamentos teóricos e metodológicos de pesquisas sobre ambientalização da escola
}

\author{
Maria Inés Copello ${ }^{1}$ \\ Universidad de la República
}

resumo Este artigo trabalha o assunto ambientalização da escola e se propõe a discutir fundamentos teóricos e metodológicos das pesquisas de Educação Ambiental que se centralizam nele. Essa concepção é considerada pelo grupo do PPGEA (Programa de Pós-graduação em Educação Ambiental, da FURG) uma das relevantes problemáticas da Educação Ambiental vinculada ao ensino formal. Conseqüentemente, o PPGEA vem realizando esforços em pesquisas vinculadas a ela. É nesse sentido que o trabalho dedica a maior parte de sua extensão a discutir o que se entende por ambientalização da escola. Por sua vez, ainda que a extensão do artigo não permita aprofundar os aspectos metodológicos, debate-se sobre a necessária relação e coerência entre a problemática e a metodologia dessas pesquisas. $O$ texto inicia-se argumentando sobre como se entende Educação Ambiental com o objetivo de desenhar um marco conceitual no qual se possa discorrer sobre a ambientalização da escola. Admite-se que unir o desenvolvimento de atitudes de resistência e responsabilidade com a valorização da solidariedade e respeito aos diferentes expressa um caminho da Educação Ambiental associada à capacitação para a ação no viés da procura de uma sociedade justa, solidária e fraterna. Em seguida - após afirmar e justificar que a Educação Ambiental não é exclusiva nem prioritariamente "propriedade" do ensino formal, mas compartilhada pelos âmbitos formal, não formal e informal -, inicia-se a explicitação do que se entende por "ambientalização da escola". A argumentação conduz à idéia de que essa ambientalização compromete a escola na sua organização e funcionamento, bem como cada um de seus membros individualmente. Afeta o currículo explícito e também o currículo

$1 \quad$ Universidad de la República, Unidad Opción Docencia, Uruguay; Fundação Universidade Federal do Rio Grande, PPGEA, Brasil, copello@adinet.com.uy 
oculto. Fundamenta-se no pensamento divergente, na criatividade, na procura de novas formas de trabalho coletivo que superem rotinas acríticas, que capacitem para a ação comprometida com uma comunidade para a qual a escola se abre, da qual se sente parte integrante e com a qual se compromete. $\mathrm{O}$ trabalho introduz o conceito de Comunidade de Aprendizagem como estratégia que pretende formar uma escola ambientalizada.

palavras-chave: ambientalização da escola, capacitação para a ação, Comunidade de Aprendizagem.

Abstract: This article deals with the subject school environmentalization and purposes the discussion of the theoretical and methodological bases of the Environmental Education researches which are centered in this subject. This conception is considered by the PPGEA group (Furg's Post-graduation Programme in Environmental Education) as one of the important questions of the Environmental Education in what refers to formal education. Based on it, PPGEA has been working in researches related to it. In this sense, the article covers mostly the discussion of what we understand by school environmentalization. Furthermore, although the article length doesn't allow us to make a deep discussion about the methodological aspects, we discuss about the necessary relation and the coherence between the question addressed by and the methodology of these researches. This article begins pointing out some arguments concerning what we understand by Environmental Education, intending to design a conceptual mark in which it is possible to discuss the school environmentalization. We admit that connecting the development of attitudes of resistence and responsibility to the appreciation of fellowship and respect to different people suggests a path for the Environmental Education associated with the qualification for action in what refers to the search of a fraternal, sympathetic and fair society. Next - after assuming and justifying that the Environmental Education is not exclusive or mostly a property of the formal teaching, but shared by the formal, no-formal and informal fields -, we begin the explicitation of what we understand by school environmentalization. The argumentation leads to the idea that this environmentalization brings damages to the school in its organization and action, as well to each of its members individually. It has an impact on the explicit curriculum and also on the hidden curriculum. It is based on a divergent perspective, on criativity, on 
the search for new ways of collective work which surpass acritical routines and capacitate for a compromising action with a community which is received, recognized as an integral part and accepted as a partner by the school. This text introduces the concept of Learning Community as a strategy which intends to form an environmentalized school.

key Words: school environmentalization, qualification for action, Learning Community

\section{Assumindo características de "uma" concepção de Educação Ambiental}

Iniciamos argumentando sobre como entendemos Educação Ambiental com o objetivo de desenhar um marco conceitual no qual discorreremos sobre a ambientalização da escola.

Concordamos com Garcia (2002) que não existe neste momento uma concepção única de Educação Ambiental' ${ }^{2}$. Ele afirma que, ao contrário, se trata de um âmbito de pensamento e ação no qual predomina a heterogeneidade e o debate, a diversidade de paradigmas teóricos, de estratégias de ação, de grupos de atuação, de cenários. Sato e Passos (2002), no mesmo caminho, falam de "vias múltiplas que tecem diferentes cores, olhares, vocês e imagens"

Como substrato comum a todas as tendências existe $o$ reconhecimento da crise ambiental e a necessidade de encontrar soluções; porém, como expressa Garcia (op. cit.), as diferenças começam a surgir no momento de analisar as causas da crise (maior ou menor responsabilidade da natureza do sistema socioeconômico) e das mudanças a realizar (moderadas ou radicais). Breiting (1997) advoga uma EA associada à capacitação para a ação, referindo-se a saber lidar com o conflito e a mudança social. Para ele, o conceito de conflito é fundamental na EA. O conteúdo dos problemas ambientais tem que ser trabalhados inter-relacionados com os conflitos de interesses que a eles se vinculam. Garcia (id.) adiciona: "Porém,

\footnotetext{
2 Educação Ambiental a partir de agora passa a ser escrita como EA.
} 
consegue trabalhar com o conflito? A conscientização pode ir além do conflito: é necessário reconhecer que a EA. vai na contracorrente em relação às concepções majoritárias de nossa sociedade, do que resulta imprescindivel o desenvolvimento da resistência e a solidariedade,"3 (p. 8). Garcia (ibid.) complementa a análise fazendo referência ao desenvolvimento de um termo onipresente nas declarações e definições dos especialistas: responsabilidade. $\mathrm{O}$ autor diz que na maioria das declarações se fala de desenvolver conhecimentos que levem à responsabilidade crítica ou se faz referência a auxiliar os grupos sociais a desenvolver seu sentido da responsabilidade. Sato e Passos (2002) afirmam que o maior desafio da EA. é a busca da alteridade - o respeito aos diferentes. "É preciso desejar a transformação social através da participação de idéias plurais contidas na essência reflexiva para uma Terra com mais responsabilidade Ecológica” (p. 115).

Em nossa perspectiva, unir o desenvolvimento de atitudes de resistência e responsabilidade com a valorização da solidariedade e respeito aos diferentes expressa um caminho da EA associada à capacitação para a ação no viés da procura de uma sociedade justa, solidária e fraterna.

Novo (1996), ao encontro dessas argumentações, propõe analisar o substrato ético que define tanto as relações inter-específicas dos humanos com o resto da natureza, quanto as relações intra-específicas dentro do gênero humano. Diz que "educar significa auxiliar as pessoas não somente a conhecer a razão instrumental de seus atos senão, sobretudo, auxiliá-las a compreender qual é o substrato ético que os orienta - o por que e o para que de suas ações - (p. 71). Nesse sentido, ela propõe superar o estar "frente" ou "com" a Natureza para perceber o ser humano como alguém "na" Natureza, alguém cuja existência tem que transcorrer em harmonia com as demais espécies e o resto do natural e cultural. Na mesma linha de pensamento, Grün (1996) propõe uma relação hermenêutica entre seres humanos e demais seres da natureza." A hermenêutica filosófica situa sempre o ser humano no mundo, na história e na linguagem e não como um sujeito

3 Esta e as demais traduções apresentadas são de nossa autoria 
senhor de si, separado dos objetos. Os seres humanos estão sempre inexoravelmente inseridos no círculo hermenêutico...Por intermédio da hermenêutica o velho esquema que preconiza a distinção entre sujeito e objeto é superado"(p.. 102).

É na concordância com essas concepções que nos introduzimos no debate do que entendemos por "ambientalização da escola".

\section{Ambientalização da escola, capacitação para a ação e comunidades de aprendizagens: encontros e conexões.}

Afirmamos, primeiramente, que a EA não é exclusiva nem prioritariamente "propriedade" do ensino formal. Entendemo-la compartilhada pelos âmbitos formal, não formal e informal. Assim, esse empreendimento educativo passa a ser responsabilidade de toda a sociedade, e a escola, por sua vez, recebe impulsos para se abrir à comunidade.

Neste contexto, explicitamos o que entendemos por "ambientalização da escola" vinculando-a com a EA, que tem por objetivo 'capacitar para a ação'. Isso incidirá numa escola que passa a assumir compromissos com sua comunidade e se abre para a mesma. Sobre tal base, introduzimos as Comunidades de Aprendizagens como estratégia que contribui para conformar uma escola ambientalizada.

Entendemos por ambientalização da escola a transformação de sua organização, de seus conteúdos e das relações entre as pessoas que formam parte dela, de modo que sejam coerentes com concepções que valorizam a construção de uma sociedade justa, solidária e fraterna ${ }^{4}$ (Pujol, 1998a, 2001). "O desenvolvimento da capacidade de atuar não é conseqüência da realização de atividades pontuais, mas da imersão dos alunos em ambientes que põem em prática o que predicam" (Sanmartí e Pujol, 2002, p. 50).

A caracterização de aprendizagem que aparece em Sanmartí e Pujol (2002) vem ao encontro das concepções discutidas e trabalhadas

\footnotetext{
4 Trazemos ao encontro disso os princípios de eqüidade e solidariedade sincrônica e diacrônica expressos por Novo (1996) e o princípio de alteridade argumentado por Sato e Passos.
} 
nas pesquisas desenvolvidas no PPGEA5. Elas expressam que é a própria comunidade educativa quem deve identificar problemas $\mathrm{e}$ propor alternativas de solução, analisando-as, medindo-as, fazendo tomadas de decisões e aplicando-as. Além disso, toda essa atividade tem que ser resultado de interações sociais que se produzem no grupo pelo compartilhamento de idéias, objetivos, sentimentos, emoções. "Interações que potenciem um processo de negociar a atividade, vinculadas por sua vez a um progressivo transpasso [aos alunos] do controle e responsabilidade que estimule a auto-regulação do processo por parte dos alunos/as". (Copello, 1998, p., 83).

Afirmar a importância do grupo e sua participação ativa no processo não significa negar nem desvalorizar o papel mediador do professor ou professora. Esse estímulo à auto-regulação não significa negar seu imprescindível papel mediador. É fundamental ter presente o papel do professor como membro do grupo que facilita a aprendizagem, permite ao aluno atuar na ZDP, atua como "andaimaje", no dizer de Bruner ${ }^{6}$ (Copello, 1998).

Então, fazendo nossas as considerações de Sanmartí e Pujol (2002), diremos que a ambientalização da escola compromete esta em sua totalidade, sua organização e seu funcionamento, assim como o faz a cada um de seus membros individualmente. Afeta o currículo explícito e também o currículo oculto. Fundamenta-se no pensamento divergente, na criatividade, na procura de novas formas de trabalho coletivo que superem rotinas acríticas.

Acreditamos que hoje em dia no Brasil a Educação Ambiental está presente na maioria das escolas de ensino básico. É uma exigência estabelecida pela Constituição de 1988 que se concretiza na forma de lei na "Política Nacional de Educação Ambiental" de 1999. Os sistemas educativos, tanto estaduais quanto municipais, estão apoiando

5 PPGEA: Programa de Pós-Graduação em Educação Ambiental, Fundação Universidade Federal do Rio Grande (FURG).

6 São feitas referências ao conceito vigotskiano de "zona de desenvolvimento proximal" e ao conceito de Bruner do professor construindo "andaimes" que auxiliem no processo, considerando, contudo, que eles poderão e deverão ser eliminados posteriormente (no momento em que aquele processo atinja a capacidade de autoregulação). 
projetos de EA e destinam profissionais de seus quadros à coordenação dos mesmos.

Porém, nossa perspectiva é de que, a despeito de todas essas iniciativas, a realidade das escolas encontra enormes dificuldades em assumir os novos pressupostos. As iniciativas existentes são marcadas pelo entusiasmo, dedicação e crença em novos paradigmas sociais; falta, contudo, maior solidez em concepções teóricas e metodológicas. Apropriando-nos da metáfora de Pujol (1998), entendemos que a EA se apresenta como "uma faca ou uma navalha" que, algumas vezes, "atravessa" com sua "lâmina afiada"o currículo da escola tradicional. Ela se faz presente em determinadas datas, tais como "Semana do Meio Ambiente", "Dia da Árvore", "Dia do Índio", na forma de campanhas ou projetos isolados (organização de uma horta e campanhas de recolhimento seletivo de lixo), ou é apresentada como aspecto adjacente ao currículo normal (falar do "buraco na camada de ozônio" ou "da chuva ácida" ao trabalhar o assunto "ar" em ciências na $5^{\mathrm{a}}$ série ou no ensino de química na $8^{\mathrm{a}}$ série).

Pujol (1998) contrapõe a Educação Ambiental "faca-navalha" à Educação Ambiental "infusão”, que, da mesma forma que a essência que se difunde na xícara de chá, se introduz, passa a permear e penetrar todo o currículo escolar. Essa metáfora nos situa no que conceituamos como "ambientalização da escola". Sua vinculação com o "capacitar para a ação" será o assunto do qual nos ocuparemos a seguir.

\section{A ambientalização da escola vinculada ao "capacitar para a ação".}

O conceito de ação associado à EA não é novo (Sanmartí, 1996). Ele foi introduzido em contraposição à visão tanto da aprendizagem de conteúdos sobre problemas ambientais quanto à de atividades no meio das quais somente se pretendia sensibilizar e dar informação. Porém, Breiting (1997), ao teorizar sobre a idéia de capacitação para a ação, a situa como centro da atividade educativa e a associa com uma visão de EA que implica mudanças de paradigma social, superando a EA reprodutora da sociedade atual. Nessa concepção, a EA implica desenvolver capacidades que permitam intervir conscientemente na 
tomada de decisões individuais e coletivas vinculadas àquelas que conformam a convivência numa sociedade democrática. Isso significa vincular a capacidade para atuar com o pensamento crítico, a reflexão e a participação. Segundo Sanmartí e Pujol (2002), trabalhar nessa conceituação de EA significa capacitar para:

1) Reconhecer que existe possibilidade de atuar, 2) Reconhecer a possibilidade de participar nas mudanças, 3) Ter vontade de atuar e ter iniciativa para concretizar as ações.

As autoras discutem as dificuldades advindas dessa concepção de EA. Fazem referência a uma pesquisa relativa às idéias dos alunos sobre as causas dos problemas ambientais e as possíveis soluções e afirmam que eles são portadores de concepções espontâneas "inatistas" : a espécie humana se caracteriza pelo individualismo e pela busca de proveito pessoal, sendo impossível mudar aquilo que é genético. Também analisam pesquisas sobre inconsistências e bloqueios que se produzem ante crises ambientais que levam a atenuar o negativo e aceitar o "inevitável". "Em situações que são negativas e inevitáveis, as pessoas se defendem adequando suas atitudes, crenças e juizos para minimizar cognitivamente o negativo da situação. Convencem-se a si mesmas que, 'ao final, a coisa não é para tanto'," (Sanmartí e Pujol, 2002, p.50).

Garcia (ibid.), avançando na clássica concepção de Lucas a respeito do "sobre", "no" e "para" o ambiente, argumenta que nessa visão o "para" significa "O meio como algo a se proteger e cuidar"( 5). Essa visão, alega Garcia, é ambientalista e se contrapõe à realização da mudança social.

Mayer (1998), também analisando essas concepções, traz interessantes colocações com relação à necessidade de superação do "sobre" e do "no". Diz que na educação sobre o meio se pressupõe que os problemas ambientais são causa da "falta de conhecimentos" e que a

\footnotetext{
${ }^{7}$ Segundo o dicionário Aurélio, inatismo: "Doutrina que admite a existência de idéias ou princípios independentes da experiência" .
} 
solução, portanto, está na informação: "Se a gente soubesse, não se comportaria assim". Argumenta que a situação é muito mais complexa: "conhecer os riscos não é suficiente e, de fato, não por casualidade, os paises mais contaminados são aqueles nos quais não só a ciência e a tecnologia estão mais desenvolvidas, mas também a visão de educação ambiental [sobre] figura na maioria dos textos didáticos em uso" (p. 219). Em relação ao desenvolvimento nos anos 80 da educação no ambiente, com base no reconhecimento de que o comportamento está guiado muito mais pelas emoções e valores do que pelas informações, o autor diz que " a teoria implícita é que o vínculo emotivo com a natureza, o sentimento que se intenta suscitar será suficientemente forte para dar impulso às mudanças comportamentais"'(p..219). No entanto, isso também se demonstrou insuficiente, não só pelo fato de a sua estruturação ser um processo lento e difícil, mas "porque o conceito de meio ambiente que contempla - meio natural a conservar e proteger - contribui para criar uma nova esquizofrenia: protegemos o ambiente 'natural' $e$ degradamos cada vez mais o ambiente em que vivemos" (p.220).

Retomando as argumentações de Sanmartí e Pujol (2002), entendemos que a "capacitação para a ação", além de trabalhar com os alunos para reconhecer que existe possibilidade de atuar, reconhecer a possibilidade de participar nas mudanças e ter vontade de atuar e ter iniciativa para concretizar as ações, necessita da existência de grupos sociais que 'atuem', que encontrem prazer nisso e que estruturem ambientes emocionalmente estimulantes. "De fato", dizem as autoras, "os valores (e os contravalores) associados à capacidade de atuar criticamente se aprendem sobretudo porque se 'grudam' como resultado de ser membro de um grupo social que os proclama, os argumenta e os põe em prática, e não porque se reconheçam as vantagens reais dos novos pontos de vista. Essa incorporação e o conseqüente compromisso dependem em boa parte de que a pessoa se sinta aceita e valorizada pelo grupo; caso contrário, tenderá a divergir e a se isolar'”(p. 50).

A discussão sobre como poderemos concretizar "ambientes emocionalmente estimulantes" nos conduz ao outro tripé desta 
argumentação: As Comunidades de Aprendizagens como espaços e contextos que vêm ao encontro da ambientalização da escola.

\section{Comunidades de Aprendizagens: contexto que vem ao encontro da ambientalização da escola.}

Avancemos na necessidade de considerar como parte do processo de aprendizagem a existência de ambientes emocionalmente estimulantes.

Reina Reyes ${ }^{8}$ (1971) censura em seu livro a insígnia da UNESCO, de 1970: Ano Internacional da Educação. Essa insígnia, idealizada pelo escultor francês de arte cinética, Victor Vasarely, está composta por anéis concêntricos que representam uma cabeça abstrata do homem universal "iluminado" pelo conhecimento que se origina num ponto situado no centro de sua frente:

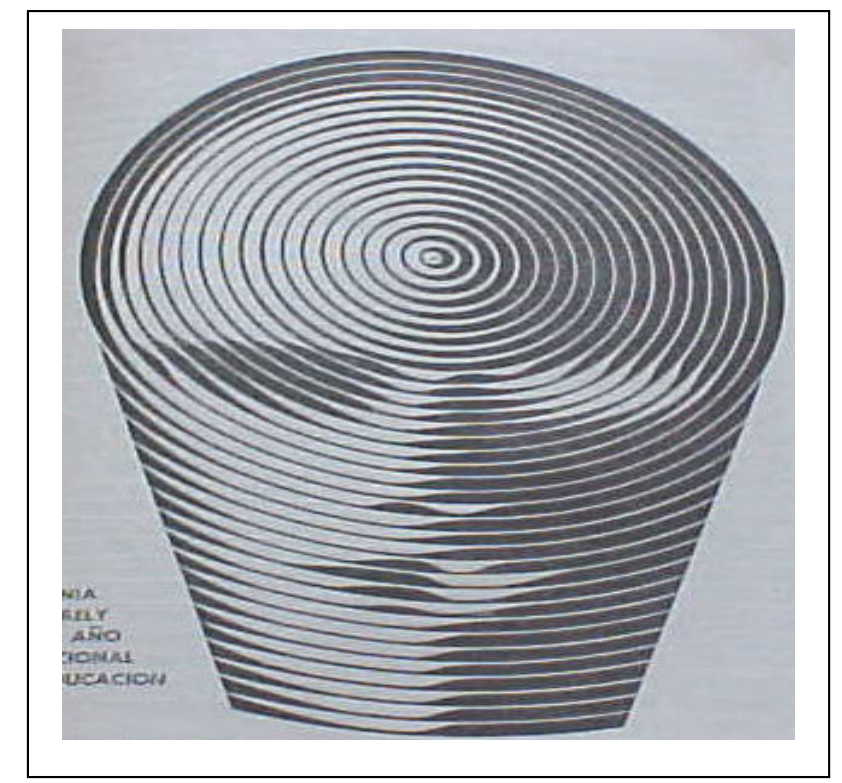

À medida que a relação entre o racional e o irracional adquire um caráter doentio, as instituições educativas não podem defender o homem, pois seguem sendo herdeiras do Iluminismo [...] Os valores físicos, sociais, afetivos, estéticos, religiosos e filosóficos ficam sacrificados ante o conhecer como suprema meta da educação (p. 94) [...] Somente conseguiremos atingir estatura

${ }^{8}$ Reina Reyes foi uma educadora que contribuiu para a nossa formação na década do 70. Hoje admiramos mais do que nunca sua capacidade de se adiantar ao seu tempo. 
humana se orientarmos nossas crianças e jovens para a flexibilidade intelectual, juízo crítico e estabilidade emocional, que, ao mesmo tempo em que afirmem sua personalidade, tornem possível sua união com os outros para uma personalidade, tornem possível sua união com os outros para uma empresa comum por aspirações compartilhadas (Reina Reyes, 1971, p. 13).

$\mathrm{Na}$ atualidade, seguindo a mesma linha de raciocínio, Orellana (2002) coloca que já não se trata de acumular saberes, que em outras épocas foi a chave do "progresso", mas de construir saberes que sejam significativos, que contribuam para mudar comportamentos individuais e coletivos, que permitam fazer frente às tendências destrutivas e (re)criar novas relações com o meio de vida. ${ }^{9}$ Vinculado a isso, defende que se leve em consideração a dimensão social como "chave" no processo de gênesis do saber e, citando Freire, diz que o saber se produz na complexa relação de reciprocidade que o ser humano desenvolve com o mundo, na qual a prática social é um elemento crucial.

Vygotsky (1989) propõe a construção do conhecimento num processo de interação social e elabora o conceito de ZDP, no qual podem ser analisados numa perspectiva processual e social as relações educativas professor/a e alunos/as. Nessa abordagem, a educação é considerada de forma indissociável em relação às realidades social, cultural e histórica ${ }^{10}$

Orellana (2002) apóia sobre as bases das concepções vygotskianas a teoria das Comunidades de Aprendizagens (CA), tendo como orientação a idéia de interação dialógica nas relações educativas que produzam condições estimulantes e significativas, além de valores comuns que tenham como finalidade gerar um saber-ser, saber-fazer e saber-viver juntos solidária e responsavelmente. Para a autora, é na procura desses objetivos que surge a idéia mesma de CA.e se revela a sua importância e adequação à Educação Ambiental. Adiciona ainda que a CA integra o enfoque comunitário, a participação, a cooperação,

\footnotetext{
9 Orellana conceitua como meio de vida "um complexo conjunto formado pelo meio ambiente, os elementos socioculturais e históricos e suas relações". Outros autores entendem esse complexo conjunto como a denominação de meio ambiente

${ }^{10}$ Sobre esses conceitos, ver Moll, "Vygotsky e a Educação" Implicações pedagógicas da psicologia socio-histórica, Artes Médicas. Porto Alegre, 1996.
} 
a interdisciplinaridade, a resolução de problemas, o vínculo entre o processo educativo e a realidade social, a aprendizagem reflexiva na ação e o enfoque democrático. Ela se vincula à noção de comunidade, resgatando seus valores essenciais e seu rol de mediadora entre a pessoa e a sociedade.

A autora coloca como estreitamente relacionada à Comunidade de Aprendizagem a noção de relação dialógica. Este é um conceito no qual temos centrado todo um trabalho de pesquisa na formação de professores (Copello, 1998, 1998a, 2001). Nós o entendemos como o processo de diálogo co-regulado em um grupo que vai levando à estruturação de uma comunidade crítica de reflexão e ação situada num contexto sociocultural concreto, ao qual se vincula tanto os meios quanto as finalidades que se propõe. Gadotti (1998), com base na idéia freiriana que vincula ao diálogo duas dimensões dialeticamente interligadas e indissociáveis - reflexão e prática -, adiciona e associa a problematização que estimula a integração de saberes e a interdisciplinaridade.

"De um ponto de vista hermenêutico, trata-se de assegurar a intersubjetividade da compreensão da comunicação, chave do diálogo, sem perder de vista o contexto cultural no qual o mesmo é gerado." (Orellana, 2002, p. 223). A autora relaciona a Comunidade de Aprendizagem com o que entende como Comunidade Educativa, e esta com a Sociedade Educativa:

1- Comunidade de Aprendizagem: Grupo organizado que adota objetivos educativos, implementa um conjunto de estratégias pedagógicas segundo um enfoque sócio-construtivista crítico que se centra num projeto concreto de co-aprendizagem, de formação, de pesquisa, de resolução de problemas ou de desenvolvimento comunitário.

2- Comunidade Educativa: Diferentes membros de uma comunidade desenvolvem laços educativos de colaboração e diálogo sobre preocupações comuns. 
3- Sociedade Educativa: As instituições e membros da sociedade participam ativamente num processo educativo contínuo e permanente.

Nessa concepção, entendemos a CA como uma estratégia privilegiada para a ambientalização da escola. Torres (2003) considera que construir uma CA implica rever a distinção convencional entre comunidade e escola e aproximar e vincular os âmbitos de educação formal, não formal e informal. "A comunidade de aprendizagem adota uma visão integral e sistêmica do educativo, colocando no centro a aprendizagem e a cultura em sentido amplo" (p..24).

A Comunidade de Aprendizagem cria condições particularmente ótimas para implementar processos dialéticos de construção da relação com o meio ambiente e o meio de vida, desenvolvendo laços de pertença e de identidade, promovendo o respeito, a solidariedade e a responsabilidade. Compartilhando esse processo, seus membros vivem uma progressiva maturidade e aprendizagem coletiva que permite penetrar na realidade de forma lúcida, compreendê-la, apropriar-se dela, objetivá-la, aprendendo a atuar ativa, comprometida e responsavelmente nela. (Orellana, 2002, p.. 228).

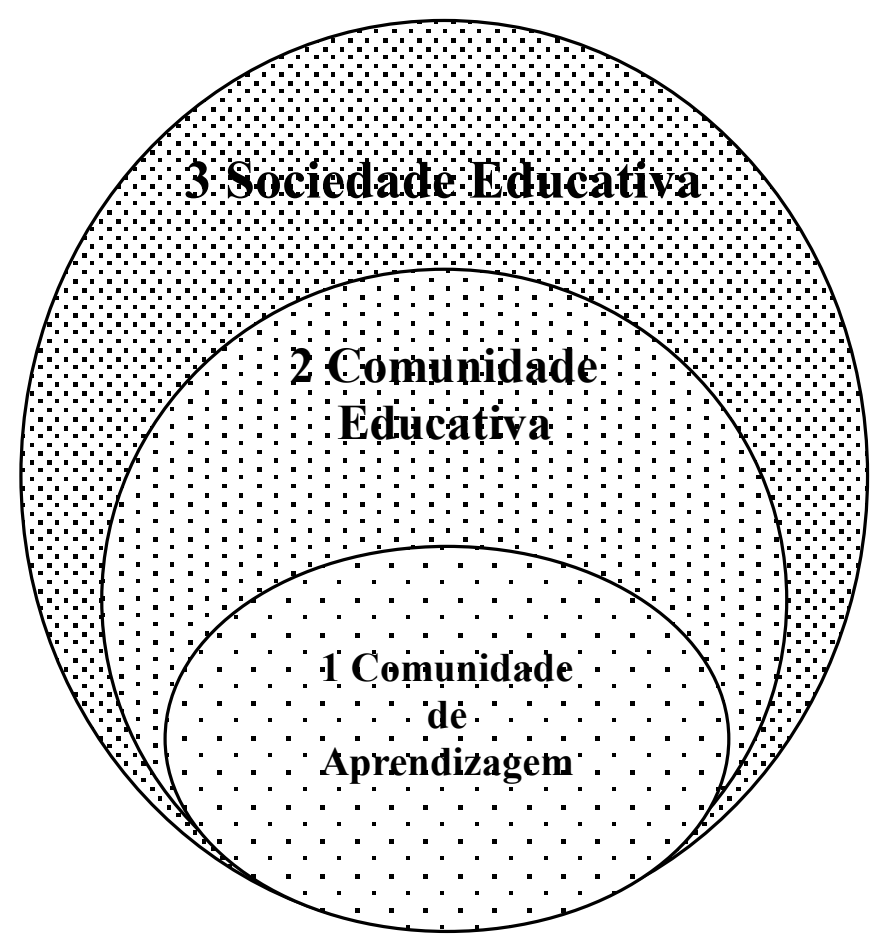




\section{Caminhos metodológicos das pesquisas sobre a ambientalização da escola}

Até aqui temos procurado caracterizar o problema central objeto das pesquisas em que estamos envolvidos: "a ambientalização da escola". Nosso grupo de pesquisa tem se deparado com trabalhos que, desde diferentes perspectivas, encaram questões referentes a esse assunto central. Neste capítulo, procuraremos tecer algumas considerações sobre outro aspecto que consideramos tão relevante quanto estabelecer o problema que nos propusemos investigar, ou seja, de que forma e em que orientações metodológicas se encontram perspectivas que viabilizem boas sendas para tecer respostas às indagações elaboradas. A metodologia empregada numa pesquisa, tanto na coleta quanto na análise dos dados, é fundamental para o êxito do trabalho. Temos que estar bem atentos para não confundir delineamentos qualitativos e abertos a reelaborações durante $\mathrm{o}$ processo de pesquisa com a falta de planejamento metodológico.

Atualmente, é aceito por grande parte da comunidade de pesquisadores da área educacional, sobretudo nas pesquisas que têm por cenário a sala de aula, o escasso significado do conhecimento de estatísticas e dados numéricos, que geralmente se tornam abstratos e sem contexto ${ }^{11}$. Incluímo-nos nessa postura e entendemos que muitas das questões pedagógicas só podem ser esclarecidas com o desvelamento do cotidiano da realidade educacional. Nesse sentido, já faz tempo que as pesquisas em educação têm se preocupado menos com a quantificação dos dados e mais com a análise desses dados, considerando sua contextualização e seu significado no processo educacional.

As pesquisas que dão conta desse tipo de enfoque inicialmente foram unidas sob a denominação de qualitativas, contrapondo o uso deste termo às pesquisas quantitativas, próprias da tradição positivista.

\footnotetext{
11 Referimo-nos às metodologias quantitativas, amplamente utilizadas dentro do paradigma positivista. Ainda que essas não venham sendo utilizadas pelo nosso grupo de pesquisa, validamos em algumas situações a combinação de métodos quanti e qualitativos.
} 
Porém, André (1995) sugere que o tipo de pesquisa a ser realizada deve receber denominações e caracterizações mais precisas. Concordamos com a autora e, nas pesquisas que nosso grupo está realizando, temos abordado e procurado delimitar diferentes metodologias, todas elas qualitativas. Entendemos isso como fundamental e de importância amplificada quando se decide trabalhar dentro deste universo qualitativo. Temos podido constatar a existência de investigações que, amparadas na decisão de serem trabalhos qualitativos, passam a omitir definições metodológicas, o que pode levar - e tem levado algumas vezes - a aprofundar reflexões teóricas, trabalhadas de forma excessivamente superficial em relação à questão objeto da pesquisa. Também temos constatado o uso de instrumentos de coleta de dados qualitativos, como questionários, entrevistas, histórias de vida, que não foram suficientemente planejados nem definidos segundo critérios precisos no momento de realização da análise.

É obviamente impossível, dentro dos limites deste artigo, se deter nos diferentes delineamentos metodológicos que poderão vir a ser utilizados em vinculação com as pesquisas realizadas. Constituímos um grupo de pesquisa que trabalha na linha "Formação de Professores e Inovação Curricular". Isso deriva em problemáticas que partem do conceito central de "ambientalização da escola" e têm levado à escolha de diferentes delineamentos, adequados a diferentes problemas e diferentes contextos de investigação. Os trabalhos realizados pela equipe, até o presente momento, têm-se utilizado de conceitos da Análise de Conteúdos Fenomenológicos trabalhados por Morais (1999), da Fenomenologia da Percepção de Merleau-Ponty (1971), Hermenêutica e Biorregionalismo (Grün, 2003), da Etnografia Escolar (André, 1995).

A extensão prevista para este texto impossibilita trazer à cena a consideração de pesquisas realizadas nesse âmbito. Gostaríamos de discutir as problemáticas ao redor da qual trabalham e considerar a coerência entre estas e os delineamentos metodológicos, o que poderá ser apresentado em outras oportunidades. 
Porém, não podemos deixar de fazer referência, ainda que rapidamente, à coerência entre a forma como se procura estruturar o grupo de pesquisa e os referentes teóricos que lhe dão embasamento. O trabalho de pesquisa de cada um pertence não só a si mesmo, mas ao grupo $^{12}$. A pesquisa vai tomando forma no seio da equipe, pertence ao "nós", nos escutamos uns aos outros. Busca-se o consenso ou o dissenso debatido no seio do grupo de "amigos críticos". A força dos entendimentos não está em quem fala mais ou fala menos, está no valor dos argumentos. O acerto é válido intersubjetivamente e é tão importante quanto o conteúdo do processo seguido para chegar ao mesmo.

\section{Conclusão}

Este artigo não teve como proposta discutir fundamentos teóricos nem metodológicos prontos e aprofundados em relação ao conceito de "ambientalização da escola". Ao contrário, temos plena consciência de que esse é um conceito em construção. Porém, compartilhamos a posição de muitos colegas que, ao redor do mundo, estão envolvidos nesta caminhada sobre a potencialidade do mesmo para a melhoria da qualidade da escola e da educação formal.

É nesse sentido que pedimos aos colegas que venham a ter em mãos este texto e se proponham a lê-lo, entendendo-o como um convite ao diálogo crítico e à união na caminhada de sua construção.

\section{Referências bibliográficas}

ANDRÉ, M. Etnografia da prática escolar, Papirus, Campinas, 1995.

BREITING, S. Hacia un nuevo concepto de Educación Ambiental, Carpeta Informativa del CENEAM, Ministerio del Medio Ambiente, Madrid, 1997.

\footnotetext{
12 Nosso grupo de pesquisa do PPGEA atua no seno do CEAMECIM, um centro criado em 1981, que já tem festejado seus 25 anos, mantido a partir da utopia do grupo. Falar dele levaria a todo outro artigo.
} 
COPELLO, M.I. Formación permanente del profesorado de biologia centrada en la reflexión dialógica sobre el trabajo cotidiano en el aula, Tese Doutoral, Barcelona, Servei de Publicacions-UAB, 1998.

e SANMARTI, N., Melhoria do processo ensino-aprendizagem da ciência a partir da reflexão dialógica, entre professor e orientador, das concepções e práticas (versão em disquete), $21^{\text {a }}$ Reunião Anual da Anped, 1998a.

e SANMARTI, N., Fundamentos de un modelo de formación permanente del profesorado de ciencias centrado en la reflexión dialógica sobre las concepciones y las prácticas, Enseñanza de las Ciencias, Vol 19 (2), p.. 269283, 2001

- A Educação Ambiental como eixo condutor da construção de um conhecimento escolar significativo e relevante para a vida, Anais do I Simpósio Sul Brasileiro de Educação Ambiental, pp 107 a 114, Erechim, 2002.

GADOTTI, M. A Educação contra a Educação, Paz e Terra, Rio de Janeiro, 1984.

GARCIA, J. E., Los problemas de la Educación Ambiental ¿es posible una Educación Ambiental integradora? Investigación en la Escuela, $\mathrm{N}^{\mathrm{0}} 46$, pp. 5 a 25, Sevilla, 2002 .

GRÜN, M. Hermenéutica, Biorregionalismo e educação ambiental in Textos Escolhidos em Educação Ambiental- de uma América a outra, Coord. SAUVÉ L.,ORELLANA, I. E SATO M., Les Publications ERE-UQAM, MontrealQuebec, 2003, pp.91 a 100.

. Ética e Educação Ambiental- a conexão necessária. Papirus, Campinas, 1996.

MAYER, M. Educación ambiental: de la acción a la investigación, Enseñanza de las Ciencias, 16 (2), pp. 217 a 231, ICE-UAB, Barcelona, 1998.

MERLEAU-PONTY, M. Fenomenología da Percepção, Freitas Bastos, Rio de Janeiro, 1971.

MORAES, R. Análise do Conteúdo. In: Educação. Porto Alegre, n.37, março 1999. p.7-32

NOVO, M. La Educación ambiental. Bases éticas, conceptuales y metodológicas, Editorial Universitas, Madrid, 1996.

ORELLANA, I. La estrategia pedagógica de la comunidad de aprendizaje, definiendo sus fundamentos, sus prácticas y su pertinencia en educación ambiental. In: SAUVÉ,L., ORELlANA, I. e SATO, M. Textos escogidos en Educación ambiental, de una América a la otra, Tomo 2, pp. 221 a 231, ERE-UQAM, Université du Québec, Montreal, 2002. 
PUJOL, R. M. Material didáctico xerocado, Curso de Educación Ambiental para profesores chilenos, Universidad Autónoma de Barcelona, Barcelona, 1998. - El procès metodològic de l' ambientalizació curricular. In Seminaris d' ambientalizació curricular. Generalitat de Catalunya, Barcelona, 1998 . Ambientalizació curricular, Perspectiva Escolar, Barcelona, 2001.

REYES, R. ¿Para qué futuro educamos? Biblioteca de Marcha. Montevidéu, 1971.

SANMARTÍ, N., El aprendizaje de actitudes y comportamientos en relación a la Educación Ambiental: reflexiones desde el área científica, in NUÑO T. \& MARTÍNEZ K. (Eds) Educar ao favor del medio, Universidad del País Vasco, Bilbao, 1996.

e PUJOL, R.M., ¿Que comporta capacitar para la acción? Investigación en la Escuela, No 46 , pp. 49 a 54, Sevilla, 2002

SATO, M. e PASSOS L.A., Versos e reversos da diversidade, Anais do I Simpósio Sul Brasileiro de Educação Ambiental, pp 115 a 123, Erechim, 2002.

TORRES, R.M., A educação em função do desenvolvimento local e da aprendizagem, Patio, revista pedagógica, Monográfico: Comunidades de Aprendizagem, $\mathrm{N}^{\mathrm{o}}$ 24, pp 22 a 25, Artes Médicas, Porto Alegre, 2003

VYGOTSKY, L.S., Pensamento e linguagem, Martins Fontes, São Paulo, 1989. 